\title{
A PHARMACOLOGICAL STUDY OF AFFERENT IMPULSES FROM THE SMALL INTESTINE
}

\author{
MASATAKA EGAMI \\ Department of Pharmacology, Kyushu University, Faculty of Medicine, Fukuska \\ Received for publication November 27, 1954
}

\section{INTRODUCTION}

William Harvey and von Haller obscrved that the viscera in man and animals were insensitive to touch and injury. More recently Lennander (1902) (1) and many other surgeons asserted that the intestine was insensitive to trauma such as cutting, crushing, burning or stretching. Meyer (1919) (2) reported that pain was induced in the mesentery and not in the intestine.

Sherrington (1906) (3), on the other hand, assumed the prescnce of receptors in the intestine from the fact that stimulation of the intestine was followed by reflex responses in the animal. Still more recently there came a good many reports on intestinal reflex from Sjöstrand and von Euler (1946) (4), Youmans (1949) (5), Semba (1953) (6) and many other workers. Gernandt and Zotterman (1946) (7) recorded and analyzed afferent impulses from the mesenteric nerve. Downman, McSwiney and Vass (1948) (8) made a more detailed report on the sensitivity of the small intestine. Kimura (1951) (9) reported that acetylcholine induced the sensation of pain practically everywhere in the abdominal viscera. Some sensory cndings were discovered in the duodenum by Seto (1948) (10) and in the jejunum and sigmoidal colon by Kimura (1953) (11).

These reports leave no room for doubt that the intestine has some receptors in it and that afferent impulses from the intestine may cause a consequential reflex in the nervous, vascular and respiratory systems. It is therefore deplorable that no noteworthy pharmacological inquiry has yet been made into the significant problem as to how drugs act on such afferent impulses from the intestine.

Procaine and dibucaine (nupercaine) applied locally obviously have a blocking action on sensory nerve endings. Furthermore it has been demonstrated by Fleckenstein (1950) (12), Kurotsubo (1942) (13), Kido (1953) (14), Tanikawa (1954) (15), Osuga (1954) (16) and others, that these drugs act efficiently on the nerve endings of the heart, carotid sinus, etc., whether they are applied locally or intravascularly.

Atropine relieves the pain of the abdominal viscera and morphine readily alleviates abdominal colic, but it remains unkown as to whether or not the former owes the therapeutic effect to the fall of the intestinal tension resulting from its parasympatholytic action, and the latter to its central analgesic action alonc. 
It is known that the calcium ion antagonizes the potassium ion by impeding the transmission of impulses in ganglia. The same action of Ca has been noted in the heart by Amann and Schaefer $(1943)(17)$ and in the carotid sinus by Osuga 1954$)(18$ )

The purpose of the present experiment is to evaluate the effect of the abovementioned drugs on impulses from the intestine by electrophysiological methods.

\section{METHODS}

Cats anaesthetized by subcutaneous injections of $1 \mathrm{~g}$ per $\mathrm{kg}$ of body weight of urethanc were used. A $3 \mathrm{~cm}$ longitudinal incision of the abdominal wall was made for exposure of the small intestine. The intestine and mesentery thus exposed were kept moist with Locke's solution at body temperature and a strip of the mesenteric nerve about $2 \mathrm{~cm}$ long was dissected. The dissected nerve was cut centrally and placed on bipolar silver clectrodes set $2 \mathrm{~mm}$ apart. The intestine was put in a shallow thermostatic bath filled with Locke's solution at $39^{\circ} \mathrm{C}$. The nerve was moistened with Locke's solution led from two reservoirs attached to the holder of electrodes during experiments. To shut out the impulses from the mesentery, the nerve was dissected as far towards the intestinal wall as possible. Afferent impulses were amplified by means of an A.C. operated R-C coupled amplifier to be observed through a Braun tube oscilloscope and recorded photographically.

\section{Peristalsis}

RESULTS

Groups of impulses of moderate potential mixed with a few fast impulses of high potential were recorded as peristalsis passed through that part of the intestine which was supplied by the dissected nerve.

\section{Mechanical stimulation}

Light touch on a part of the intestinal wall which caused no visible deformation elicited either a few large impulses or no impulse at all dopending upon the spot of the intestine touched.

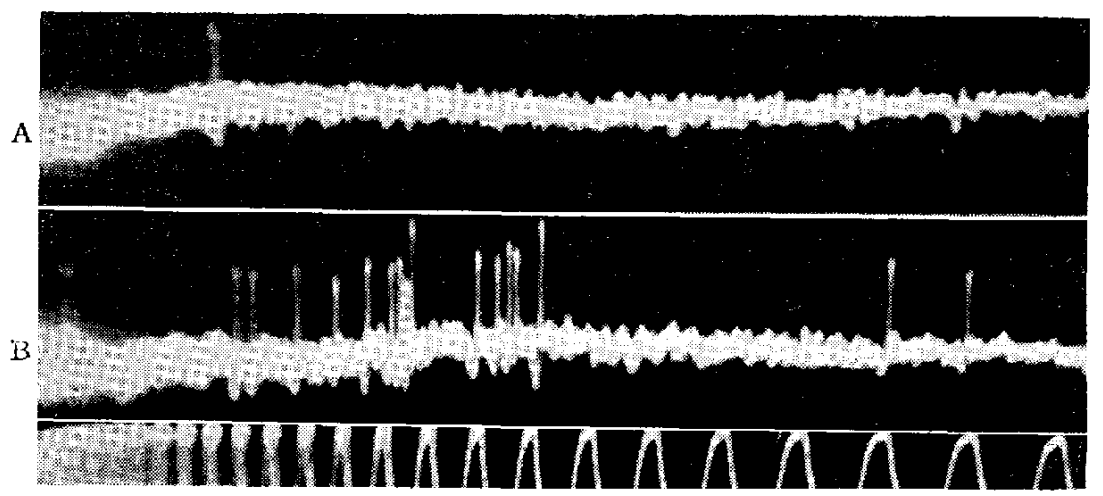

FIG. 1

A : Contro?, B: Discharge elicited by peristalsis. 
$A$ pinch given to a spot of the intestine was followed by a large number of very small slow spike potentials. In certain limited spots, these small slow spike potentials were intermixed with a few fast large spike potentials. When several different spots were pinched simultaneously, these small slow spike potentials summated to produce large waves. On such occasions the cat shook its body and expressed pain with groans and thrashing of its tail.

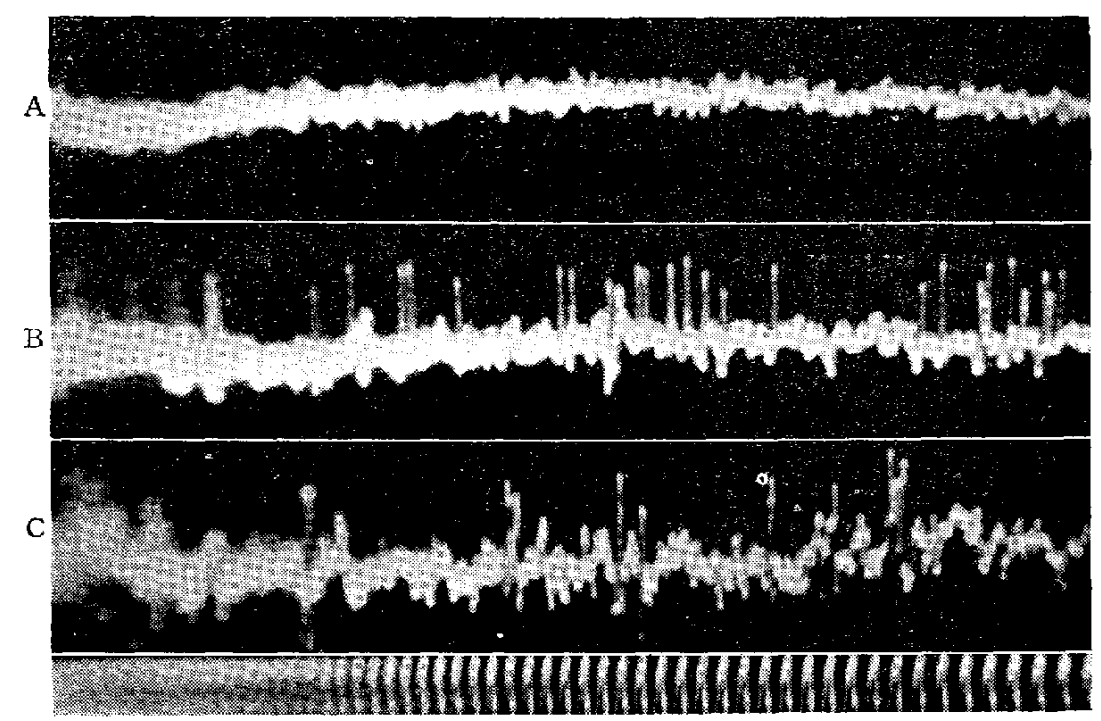

A : Control.

FIG, 2

$B$ : One spot of the intestine was pinched.

C: Five spots of the intestine were pinched simultaneously. The cat expressed pain.

When the intestine was stretched, impulses of varying sizes were elicited. While it was kept in a state of strong traction, an enormous number of small slow spike potentials grouped together and built up large potential waves intermixed with a few spike potentials of medium size, and the cat expressed obvious pain.

The intestine was closed at one end and a cannula inserted into the opposite end. The internal pressure of the intestine was raised artificially by Locke's solution at body temperature poured in through the cannula. Impulses of varying sizes were elicited when the intestine was expanded by increasing internal pressure. The spike potentials elicited when the internal pressure was kept at $140 \mathrm{~mm} \mathrm{Hg}$ or higher were similar to those recorded when the intestine was kept tautly stretched.

\section{Cosling}

Cooling of the intestine with crushed ice down to about $5 \mathrm{C}$ caused no change in the impulses, but all the impulses ceased when the preparation covered with a thin rubber membrane was refrigerated to about $-5^{\circ} \mathrm{C}$ with ethyl chloride. $\Lambda 11$ the impulses reappeared, however, when the preparation was warmed. 


\section{Acetylcholine}

Kimura (1951) (9) reported that injection of 2.5 per cent acctylcholine solution into the abdominal viscera caused severe pain in man.

Acetylcholine in the concentration of 2.5:100 applied in droplets to a part of the intestinal wall induced strong spastic contractions of this part, and the cat would shake its tail and body, and cry out as if in great pain. Relaxation follows in about 10 minutes. As the spastic contraction increased in intensity, there were recorded many small slow spike potentials intermixed with a few fast spike potentials of different sizes. When, however, the contraction reached the maximum and the cat observed to be in greatest pain, there appeared large waves produced by small slow spike potentials mixed with a few medium sized fast spike potentials. The expression of pain passed off as the intestinal contraction passed the maximum.

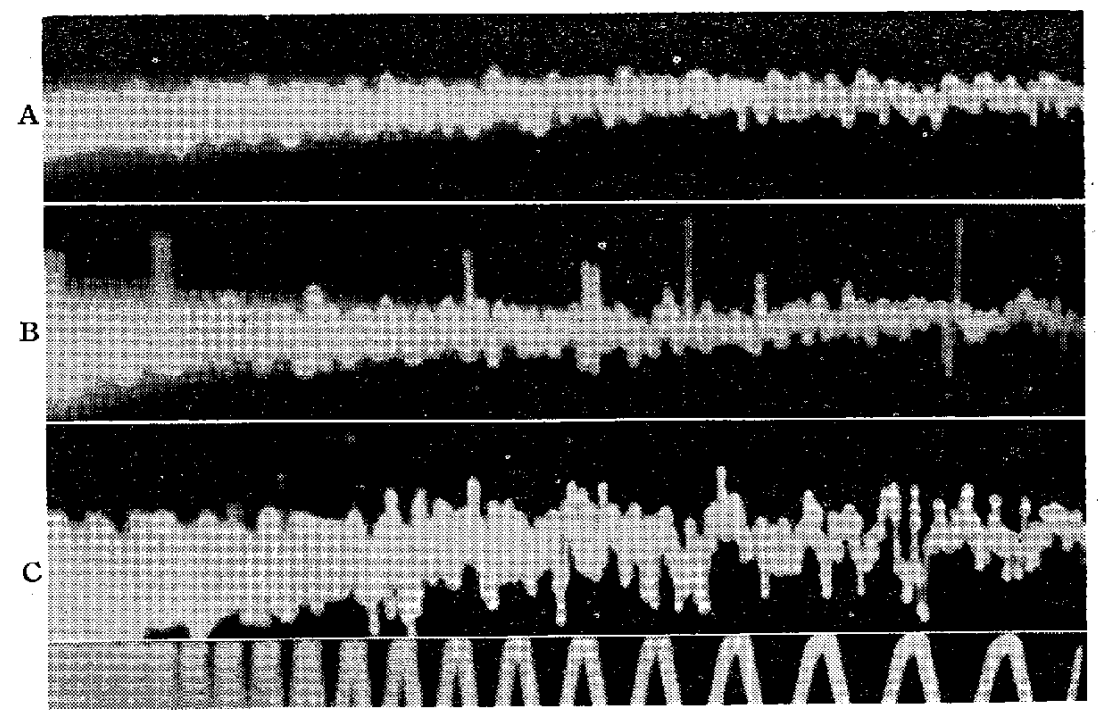

FIG. 3

A : Control.

$B$ : About 10 seconds after application of $2.5 \%$ acetylcholine solution. The intestine began to contract.

C: Three minutes after application of $2.5 \%$ acetylcholine solution. The contraction of the intestine reached the maximum. The cat expressed pain.

\section{Procuine}

Five to $10 \mathrm{mg}$ per $\mathrm{kg}$ of procaine hydrochloride given intravenously inhibited the movement of the intestine so that the impulses due to the peristalsis were reduced in number, and lowered in potential. Other impulses due to acetylcholine, pinching, stretching and expansion were lowered in potential, but not influenced in number. All impulses disappeared 5 to 10 minutes later. In this situation the cat expressed no sign of pain by the application of acetylcholine or injurious mechanical stimulation. 
Not until 30 minutes later did the effect of the drug wear off. Procaine hydrochloride was generally milder in action and ceased to act sooner in doses of $5 \mathrm{mg}$ per $\mathrm{kg}$ than in doses of $10 \mathrm{mg}$ per $\mathrm{kg}$.

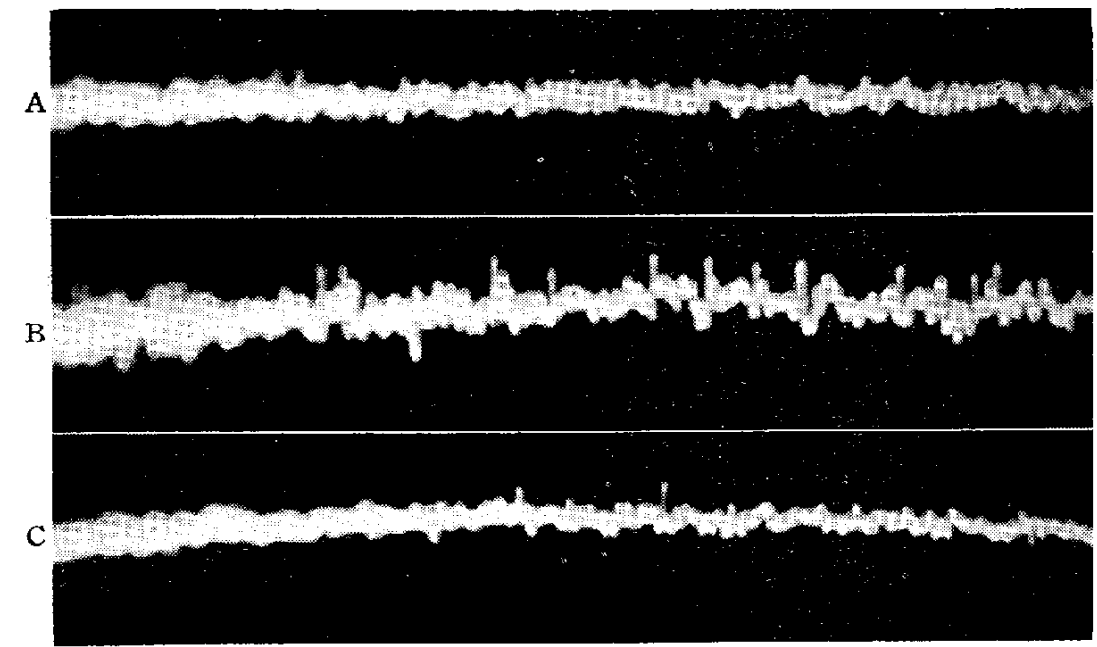

FIG. 4

A: Control.

B: The intesine was stretched cautly. The cat expressed pain.

$\mathrm{C}$ : Eight minutes after intravenous injection of $10 \mathrm{mg} / \mathrm{kg}$ of procaine, the intestine was stretched tautly. The cat did not expressed pain.

\section{Dibucaine (Nuberaine)}

Dibucaine given intravenously in doses of $1 \mathrm{mg}$ per $\mathrm{kg}$ inhibited intestinal movements and reduced the number of impulses due to peristalsis, but did not bring down the potential of all impulses as effectively as procaine did. Dibucaine given intravenously in doses of $2 \mathrm{mg}$ per $\mathrm{kg}$ lowered the potential to a considerable degree, but occasionally resulted in the death of the cat.

\section{Atrosine}

Atropine sulfate given intravenously in doses of $1 \mathrm{mg}$ per $\mathrm{kg}$ (a sufficient parasympatholytic dose) inhibited intestinal movements, resulting in a reduction or abolition of impulses. Atropine, being antagonistic in action to acetylcholine, inhibited the impulses induced by acetylcholine but had no effect on impulses due to injurious mechanical stimulation such as pinching, stretching, etc. A 0.05 per cent atropine sulfate solution applied in droplets dircctly to the dissected nerve failed to affect the conduction of impulses.

\section{Morphine}

Morphine hydrochloride given intravenously in doses of 5 to $10 \mathrm{mg}$ per $\mathrm{kg}$ of body weight slightly accelerated intestinal movements and consequently increased the num- 
ber of impulses due to peristalsis. It, however, did not affect the impulses induced by injurious mechanical stimulation and acetylcholine applied in droplets. In spite of this, the cat gave no sign of pain following thesc powerful stimuli. One per cent morphine solution dripped on the dissected nerve had no observable action on the conduction of impulses.

\section{Calcium chloride}

Intravenous injection of 20 to $40 \mathrm{mg}$ per $\mathrm{kg}$ of body weight of $\mathrm{CaCl}_{2}$ was followed in 1 to 2 minutes by inhibition of the intestinal movements, and consequently the impulses due to peristalsis almost disappeared. It did not, however, influence the impulses induced by injurious mechanical stimulation and acetylcholine applied in droplets.

\section{DISCUSSION}

\section{Discharge of deformation}

It is manifest from the foregoing results that there exist some receptors in the intestine which react to various types of deformation of this organ. In some spots the receptors are sensitive to very faint stimuli such as light touch which cause no visible deformation of the intestine.

\section{Conduction of pain}

It is also to be noted that there are small slow spike potentials remaining after the intestine has been subjected to strong mechanical stimulation. When the intestine is subjected to prolonged mechanical stimulation such as stretching or when it contracts maximally, the animal expresses pain and small slow spike potentials summate to produce large potential waves. The conduction of pain was dealt with by Zottermann (1939) (19), Gernandt (1946) (20) and Gernandt and Zotterman (1946) (7) in relation to sensory nerves of the skin, to the phrenic nerve and to the mesenteric nerve, respectively. The present series of experiments have shown that the intestine itself has a sensation of pain. It seems that waves composed of small slow spike potentials must reach a certain height for the sensation of pain to be induced.

\section{Cooling}

The receptors in the intestine lose their function as those in the skin when cooled to below $0{ }^{\circ} \mathrm{C}$ with ethyl chloride and recover their function when warmed, as observed electrophysiologically.

\section{Procaine and dibucaine}

It has recently been reported by surgeons that procaine dripped intravenously alleviates the pain felt after an abdominal operation. This is explicable from the fact that procaine given intravenously, besides inhibiting the automatic movement of the intestine, brings down the potential of afferent impulses. The present experiment 
has demonstrated that, given intravenously, procaine has a more powerful action than dibucaine upon the afferent impulses.

\section{Atropine}

The anticholinergic action of atropine has also been demonstrated in this experiment. Undoubtedly atropine has no action on impulses due to mechanical stimulation. of the intestine, nor has it any direct analgesic action on the intestine. It must be concluded that the alleviation of abdominal pain by atropine is due to the fall of intestinal tension resulting from its parasympatholytic action.

\section{Morphine}

Morphine injected intravenously increases impulses induced by peristalsis because it accelerates the movement of the small intestine. Morphine given intravenously in quantities sufficient to abolish the expression of pain do not inhibit the slow spike potentials due to injurious mechanical stimulation or acetylcholine applied in droplets. This fact shows beyond doubt that morphine has no analgesic action on peripheral nerves.

\section{Calcium}

Amann and Schaefer (1943) (17), Osuga (1954) (18) and Egami (1953) (21) have reported that $\mathrm{CaCl}_{2}$ has an inhibitory action on afferent impulses from organs other than the intestine. Injected intravenously, the drug inhibits the movement of the small intestine and reduces, as a result, impulses due to peristalsis. Fiowever, it has no influence on impulses induced by strong mechanical stimulation or by acetylcholine applied in droplets.

\section{SUMMARY}

1. Afferent impulses from the small intestine were recorded from the mesenteric nerve in the cat.

2. Injurious mechanical stimulation or strong contraction of the intestine due to acetylcholine applied in droplets induced the appearance of many small slow spike potentials.

3. For a sensation of pain to be induced, the potential waves composed of small slow spike potentials had to reach a certain height.

4. Given intravenously, procaine had a stronger action on impulses than dibucaine.

5. Atropine was found to have no direct analgesic action on the small intestine.

6. Morphine had no analgesic action on peripheral nerves.

7. Calcium chloride had practically no action on impulses from the small intestine induced by injurious mechanical stimulation and acetylcholine applied in droplets. 
Acknowledgement. These studies were performed under the helpful suggestions and criticisms by Prof. T. Fukuda and Prof. B. Nuki. The author wishes to express his deep appreciation to his respected teachers.

\section{REFERENCES}

1) IENNANDER, K. G.: Mitt. Grenzgeb. Med. Chir. I0, 38 (1902)

2) MEYER, A.W.: Dtsch. Z. Chirur. 151, 153 (1919)

3) SHerrington, C.S.: The integrative Action of the Nervous System, Scribners, New York (1906)

4) SJÖSTRAND, T. and VON EULER, C.: Oral Communication to the Physiological Society, Stockholm, March (1946)

5) Youmans, W. B.: Nervous and Neuro-humoral Regulation of Intestinal Motility, Interscience publishers, 51, New York (1949)

6) Semba, T.: $J$. Physiol. Society Jap. (Japanese) 15, 520 (1953)

7) GernandT, B. \& ZotTerman, Y.: Acta Plysiol. Scand. 12, 56 (1946)

8) Downman, C. B. B., MCSwineY, B. A. \& VAss, C.C. N.: J. Physiol. 107, 96 (1948)

9) KimuRA, Ch.: Saishin-igaku (Japarese) 6, 425 (1951)

10) SETO, H.: Advance of Medicine (Japanese) 5, 225 (1948)

11) Kimura, CH.: Arch. Jap. Chirur. 22, 59 (1953)

12) Fleckenstein, A., Muschaweck, R. And Bohlinger, F. : Arch exper. Path. u. Pharmikol. 211, 132 (1950)

13) KuRotsubo, M.: Folia pharmacol. jaśon. 34, 500 (1942)

14) KIDo, R.: Hyushu Memoirs of Medical Sciences 3, 284 (1953)

15) TANikawa, M.: Jap. J. Pharmacol. 3, 118 (1954)

16) Osuga, R.: Fyushu Memoirs of Modical Sciences 5, 1 (1954)

17) AMANN, A. \& SchaefER, H.: PJ ügers Arch. 246, 757 (1943)

18) OSUGA, R.: Kyushi Memoirs of Medical Sciences 5, 7 (1954)

19) ZotTerman, Y.: J. Physiol. 95, 1 (1939)

20) Gernandt, T.: Acta Physiol. Scand. 19, 255 (1946)

21) Egami, M.: 'íhis Journal 4, 155 (1955) 